\title{
SYMPOSIUM
}

\section{pol-casting: the use of podcasting in the teaching and learning of politics and international relations}

jason ralph, naomi head and simon lightfoot

School of Politics and International Studies, University of Leeds, Leeds LS2 9JT, UK. E-mails: j.g.ralph@leeds.ac.uk, s.j.lightfoot@leeds.ac.uk

doi: $10.1057 /$ eps.2009.38

Abstract

This article explores the use of podcasts in the learning and teaching of Politics and International Relations in a UK Higher Education institution. The article has three main sections. The first explores the pedagogic issues associated with the use of podcasts. The second highlights examples of good practice for using podcast material in lectures/seminars. Finally, and perhaps most importantly, it outlines student attitudes to the use of podcasts within learning and teaching.

Keywords podcasting; pedagogic research; US foreign policy

$\mathrm{P}$ odcasting is the newest development in e-learning, offering a novel mechanism for delivering materials and facilitating learning (see Swain, 2006). ${ }^{1}$ The term 'Podcast' is derived from 'iPod' (which is the portable multimedia player from Apple) and 'broadcast' (Lim, 2006). It is now used to describe audio (MP3) and video (MP4) files that are accessible via an internet connection. While material that is relevant to learning and teaching in Politics and International Relations (PIR) is increasingly available as podcasts, limited discipline-based pedagogic research has been carried, something this project aims to correct.
This article summarises the findings of a research project that explores the use of podcasts in the learning and teaching of PIR at the University of Leeds. It sets out to examine, within a strategy of blended learning on campus, what added-value the consumption and production of podcasts can bring to the learning process. It also aims to go some way towards identifying the 'perfect blend' of podcasting and traditional methods, which can support student learning of PIR in the twenty-first century media-rich environment.

The article has three main sections. The first explores some of the pedagogic 
issues associated with the use of podcasts. The second highlights how the team set out to use podcast material in lectures/seminars. Finally, and perhaps most importantly, it outlines student attitudes to the use of podcasts within learning and teaching.

\section{PEDAGOGIC BACKGROUND}

So, what is podcasting and how can it be used to support student learning? As we discovered, podcasting is not just about incorporating audio files into a PowerPoint presentation, or making them available through the Virtual Learning Environment (VLE) or on the internet! This is a common misconception. This is not to say there is anything wrong with this method. It is just that for purists it is not podcasting. A podcast involves placing audio files on the Internet in conjunction with a 'Really Simple Syndication Feed' or 'RSS Feed'. The RSS Feed enables files to be automatically downloaded to a personal computer the moment they are uploaded to another website. In our context, the moment a lecturer uploads a file to a module website the RSS can make certain that it is automatically downloaded to a student's PC. An RSS feed is usually a simple website address and, again in our context, it could be the website of the address where we host our educational material.

The RSS feed also works alongside what is called an aggregator. Perhaps the most well-known aggregator is iTunes. The aggregator allows students to subscribe to a podcast series in the same way that academics subscribe to journals. It is, if you like, your electronic pigeon hole, where the podcasts to which you have subscribed are delivered. To subscribe to a podcast you simply insert the RSS feed into a box on the aggregator that will usually say 'subscribe'. The aggregator will then automatically download the podcasts that are uploaded to
'The current pedagogic research that exists ... highlights several potential benefits and drawbacks with the use of podcasting'.

the website you have subscribed to. We believe this technology has much potential for changing the way we communicate with students.

The current pedagogic research that exists (Beldarrain, 2006; Campbell, 2005; Huann and Thong, 2006; the IMPALA project ${ }^{2}$ ) highlights several potential benefits and drawbacks with the use of podcasting. The main perceived benefit is that it appeals to the digital natives (Prensky, 2001). Prensky argues that 'our students are no longer "little versions of us"'. They are native speakers of technology, fluent in the digital language of computers, video games, and the internet. Many expect technology to be used in Higher Education $(\mathrm{HE})$, having been exposed to it while at school or college.

Podcasts can also map onto the chronological nature of typical HE teaching. The majority of courses are structured on a weekly basis with a different learning activity planned each week. Supporters argue that there is an advantage for students being able to get the automatic downloads rather than logging on to get the most recent resource. In addition, podcasts are relatively easy and low cost to create and distribute. Many VLEs now have recording tools as indeed do mobile phones! Therefore the staff, many of whom may be 'digital immigrants' (Prensky, 2001), could integrate the technology into their teaching relatively easily.

There is considerable research that highlights that students have different 


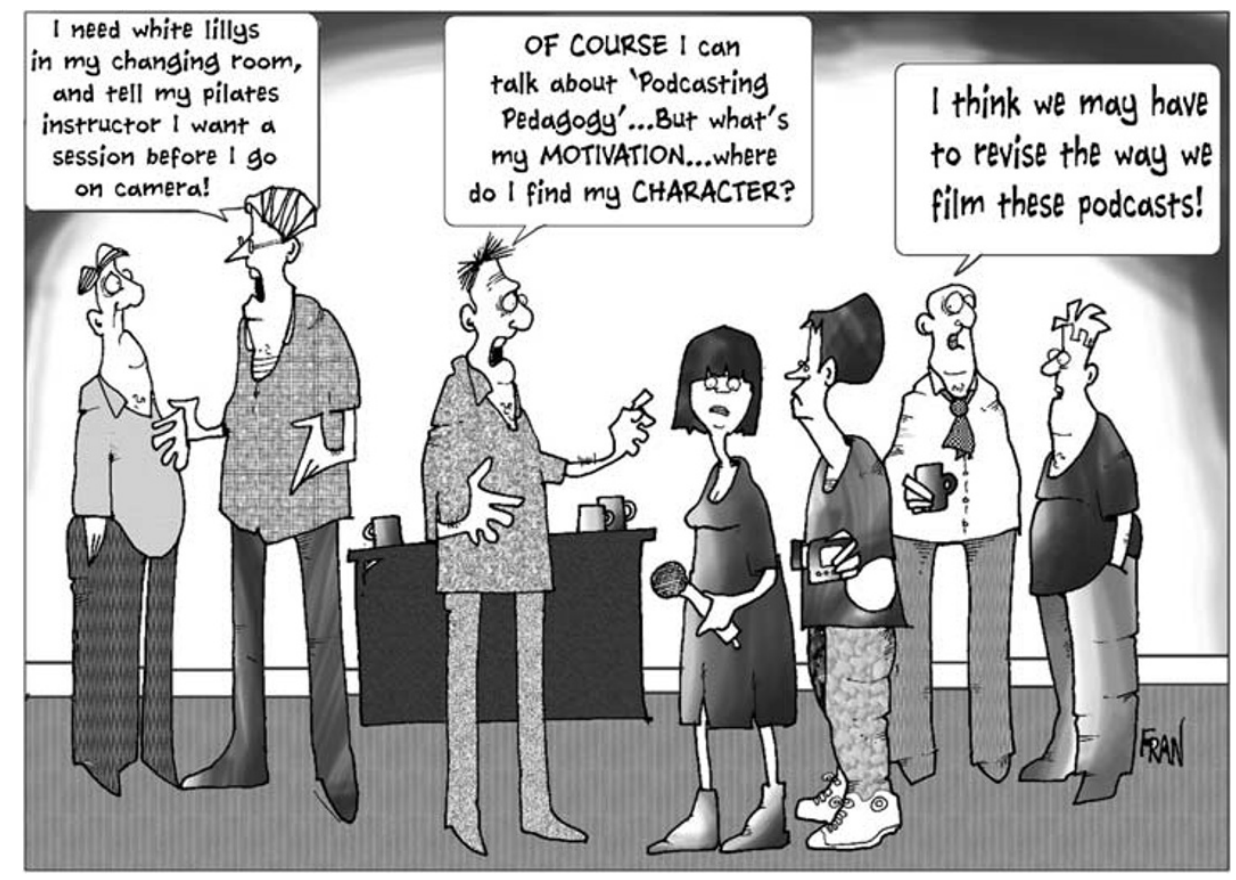

(C) fran@francartoons.com

learning styles (Visual, Auditory, and Kinesthetic) but some of these learning styles are not normally favoured by traditional teaching methods in HE. Although they do not focus on the above styles, Fox and Ronkowski (1997) have demonstrated that students in political science courses use a variety of learning styles and they suggested that instructors expand their teaching methods to address a broader number of learning styles. This finding is supported by Sims and Sims who argue that course design needs to accommodate this diversity of styles (Sims and Sims, 1995).

Podcasts clearly appeal to auditory learners, those who learn best through hearing things (Meng, 2005). One problem with traditional lectures is that you only get one chance to hear it. If you learn best via listening rather than reading this creates problems. You can re-read a text until you understand it. That option is not open to auditory learners. Podcasting lectures or seminars gives these students a choice about

where and when to access digital material and how many times they wish to repeat it (Lane, 2006). As Gribbins argues 'Recorded lectures distributed via podcast can allow students to "re-attend" class' (Gribbins, 2007).

An issue here is whether podcasting would change the balance between auditory learning and reading. In the traditional PIR course the emphasis tends be on the latter and there is perhaps a danger that the use of podcasting may raise the false expectation that a student can do well in a module without doing the necessary reading. Indeed some are now arguing that e-technologies appear to be leading many students to use 'lowest common denominator' information, with some arguing that e-technologies are more damaging to the undergraduate research and learning processes than they are worth (see Dolowitz, 2007).

It could be argued, however, that the traditional course does transfer knowledge through the lecture and that most 
examiners are familiar with the 'lowest common denominator' effect in courses that do not employ e-learning technologies. This suggests that this kind of poor student performance is not necessarily a consequence of technology and e-learning and it further suggests that the emphasis should be on how the teacher uses this kind of technology. Clearly, the undergraduate research and learning process in PIR courses requires wideranging and intensive reading. To the extent that students on these courses do use auditory learning techniques then it is possible that podcasting audio material can enhance their experience. The teacher who does not wish inadvertently to change the balance between auditory learning and reading can in fact tailor the podcast (just as they can tailor the traditional lecture) to inspire further reading and to avoid creating the impression that the MP3 player is a substitute for the library. Podcasting is merely a means of delivering teaching material, it does not dictate the nature of that material or its educational value.

Podcasts then do appeal to the auditory learners and the argument here is that used correctly they can enhance this aspect of the student's experience without inadvertently changing the student's expectation of what is required to do well in a PIR module. This potential benefit is particularly relevant as universities seek to increase their intake of international students. By enhancing that aspect of the module that relies on the auditory learning capacities of students, podcasting can assist those who are studying through a second or sometimes third language. While no one is claiming that podcasting is a substitute for contact hours, the student's opportunity to 're-attend' the class is particularly valuable for those who may have struggled to pick up everything the first time around.
Furthermore, there is evidence to suggest that the traditional 50 -min lecture is far from the most effective way of making use of the average student's attention span (Read, 2005). Lecturers support these findings with anecdotal evidence of 'losing' the students in the second half of the lecture. This might suggest a teaching timetable of shorter, more intensive, learning slots rather than dividing the traditional 8-h day into eight learning slots. Alternatively, it suggests providing the students with a means of 're-attending' the lecture in their own time, or at least having the capacity to revise those points that may have been delivered at a point beyond their attention span (see Kumar, 2003).

In this way, podcasts potentially have many benefits allowing students to listen to audio material in a wide variety of contexts to ensure full understanding of the class (Chinnery, 2006; Knight, 2006; Taylor, 2009). Other benefits include allowing students flexible access to teaching materials and adding variety to the learning experience. For staff the novel aspect of podcasts raises student interest and encourages engagement with the materials.

The pedagogic issues associated with podcasting include the fact that not all students will have access to, or be familiar with, the technology, students with some disabilities will have difficulty using podcasts, and listening to podcasts could be a passive learning activity (see SDDU, 2007). This article is not the place to engage in a full debate about whether or not current students are digital natives. However, it is clear that being familiar with certain aspects of technology such as video games, mobile phones or Facebook does not always equate to familiarity with the types of technology used in universities.

There is also the question of attendance at lectures. The availability of full lecture 
podcasts could contribute to a decline in class attendance, resulting in students failing to build up relations with their tutors or peers. They could also fail to learn crucial skills such as note taking. Supporters of podcasts argue that 'students are more likely to go to class and participate in the conversation because they are not worried about writing everything down' (Knight, 2006). Studies at the University Leeds have shown that engaging with students in a dialogue about podcasts and attendance produced no discernible drop in attendance. Research from the US supports this evidence (Roberts, 2008). In addition, the use of technology raises issues of technical support from university instructional technology departments (e.g., server space, bandwidth, maintenance), and faculty member buy-in of the use of the technology (see Gribbins, 2007).

It is worth noting that this project aims to examine how best to make the most of resources that are accessible to students using existing university infrastructure. Unfortunately, the funding for the project did not extend as far as that available to others. For example, Duke University gave iPods to 1600 first-year students! Their survey found similar responses from students about the pros and cons of using iPods as a learning and teaching tool (Duke, 2005).

\section{PRIMARY RESEARCH QUESTION}

Within a strategy of blended learning on campus, what added-value can the consumption and production of podcasts bring to the learning process within PIR? Inspired by Lim's categorisation of current practices this project focused on two parts of the same process: 'consumption' (i.e., using podcasts that are already 'out there' on the internet) and 'production' (Lim, 2006). Innovative work has
'Supporters of podcasts argue that "students are more likely to go to class and participate in the conversation because they are not worried about writing everything down" (Knight, 2006)'.

already been done in the area of production by academic staff, especially on the question of how students respond to the podcasting of the traditional lecture (see Draper and Maguire, 2007; Read, 2005). This project examined the models offered by IMPALA and developed additional applications by discovering the manner in which students can and do interact with this new technology and whether it can help address the learning and teaching needs of the PIR community. Perhaps the most innovative aspect of the project was the engagement of students in the production of their own podcasts. We hoped to engage PIR students in their use of podcasts as part of a 'blended' learning strategy that will enhance their learning experience, increase their learning flexibility and nurture their transferable skills, including presentational skills via the production of podcasts.

\section{BACKGROUND}

This project is based in one HEI in the UK: the University of Leeds. It focuses on the module PIED3402 American Foreign Policy taught by $\mathrm{Dr}$ Ralph. This is an excellent test case for two reasons. Firstly, as Singh argues, audio-visual material is an excellent way to 'enliven and enrich' the teaching of US politics (Singh, 2001: 134). Secondly, the use of podcasting as a medium for the

jason ralph et al european political science: 92010 
conduct of politics teaching and learning in $\mathrm{HE}$ is particularly pronounced in the United States (Windham, 2007). However, the use of podcasts on undergraduate modules in the field of International Relations is a relatively new phenomenon (see Roberts (2008) and Taylor (2009) as notable exceptions). We therefore needed to ensure that our use of such podcasts was not just a novel add-on to the module. Thus we carefully considered their use in light of the pedagogic research, student focus groups, and perhaps most importantly, the overall module aims and objectives.

On completion of this module, students should be able to demonstrate familiarity with the making and conduct of US foreign policy including the central ideological, procedural and historical concepts, the relevant institutions, structures and personalities. They will be able to demonstrate familiarity and critical engagement with central texts on US foreign policy and be able to distinguish authors, locate their opinions on ideological spectrums and critically assess the validity of their views. On completion of this module students should be able to develop a reasoned argument, synthesise relevant information, exercise critical judgement, and manage and self-critically reflect on, their own learning and make use of constructive feedback. They should be able to communicate effectively and fluently, use communication and information technologies to retrieve and present information. They are expected to work independently and in groups, show initiative, self-organisation and time-management.

We initially planned a variety of activities involving podcasts but after conducting a student survey, we made some changes to the project design. Our initial plan was to replace some lectures with podcasts. This was overwhelmingly rejected by the students as a suitable way of using the technology. Another initial idea was to create a pod library of commercially available podcasts, but copyright laws prevent the uploading of material downloaded from another source. Our solution was to use a social bookmarking site grazr. Social bookmarking allows those interested in a particular topic to create a link to a relevant site that like-minded individuals can follow. Our podlibrary, in other words, is a collection of links to websites that host podcasts rather than a collection of files that have been downloaded and then uploaded again. In addition, the social bookmarking site potentially allows us to create a 'community of practice' whereby we can share information with other users, which includes other users posting relevant files.

On the production side, we created 'podules' as an enhanced means of communication. Podules are small files that are produced by the project to summarise the key point of the lecture, highlight a particular issue or act as a guide to further reading or listening. These were produced weekly and therefore could be set up for an RSS feed. This follows the model of 'Profcasting' trialled by the IMPALA project (Edirisingha and Salmon, 2007), and the model employed at the University of Sydney (see Clark et al, 2007). We also asked students to produce their own podcast summaries of the seminar discussion. This mirrors work elsewhere, which has produced favourable feedback (see Lee et al, 2008). Asking students to summarise seminars can be seen as them participating in their own learning, or active learning (see Powner and Allendoerfer, 2008). Indeed Lee et al argue that the true potential of podcasting technology lies in its knowledge-creation value, and its use as a vehicle for disseminating learner-generated content (Lee et al, 2008: 504). There was also one full lecture recorded and made available via a blog. Following this model, we decided 
to host our podule files on a module blog. The blog also allowed us to overcome some space issues we encountered. We found that the size of MP3 files (an hour lecture worked out at over $49 \mathrm{MB}$ ), meant that they became unmanageable as they were hard to store without filling up drives, they could not be emailed easily and they often took time to download. We would also 'tag' these files so that they were picked up by the student's aggregator and automatically downloaded for the student when they subscribed to the module blog.

The project was affected by a number of technical problems. While the creation of the pod library was a success, it did not work quite how we intended it. In part, this was due to technological problems, which limited uploading rights to the member of the project team who had created the site. This meant that the social networking site did not function as 'the community of practice' as we intended. The other issue was how to handle large audio files. Our solution was to place the files on the module blog. This meant we could combine the storage elements of the blog with the interactivity a blog provides. This was created successfully but the fact that students had to go to a separate site for PowerPoint slides (the University 'Portal'), the blog for produced audio files as well as the social bookmarking site to consume podcasts was not necessarily user friendly. The introduction of a new VLE at Leeds should in future allow all elements to be in one place.

\section{INITIAL FINDINGS: STUDENT ATTITUDES}

Our survey was sent to all POLIS students studying Politics and International Relation. It was managed via the Bristol online survey tool using questions already asked of medical students and professionals (see Sandars and Schroter, 2007). An
'Our survey confirmed existing studies ... which showed that despite having MP3 players or phones, the majority of students listened to podcasts on their personal computers'.

incentive was offered to take part in the survey. The overall response rate was approximately 18 per cent $(92 / 500)$ which we feel is relatively good for this type of survey.

Our survey found that of the respondents 92 per cent had access to MP3 players and used them on a regular basis. There is a suspicion that these are the 'digital natives'. Our survey confirmed existing studies (Lane, 2006; Sandars and Schroter, 2007), which showed that despite having MP3 players or phones, the majority of students listened to podcasts on their personal computers. Our survey findings also confirmed the findings of existing studies, which showed how students would like this technology to be used (see IMPALA project; Clark et al, 2007). The overwhelming majority of students rejected the idea that prerecorded lectures could be used in place of the traditional lecture that required attendance. As Table 1 shows, there is a clear indication that students would prefer to use downloadable audio files as a way of reinforcing, reviewing or revising what has been discussed in the lectures. Only one respondent said they would not use the downloadable material.

As noted above, this evidence led us to change one aspect of the planned trial. Neither student opinion, nor previous research, had demonstrated any appetite for using podcasts as a substitute for the lectures, so that aspect of the trial was

jason ralph et al european political science: 92010 
Table 1: If downloadable audio files (MP3 files and podcasts) were available to support your studies, when would you most likely use these educational materials? Please only choose one option

In place of attending lectures

As a way to reinforce or review what has been discussed in a lecture

As a revision aid before exams

Not at all
$6.9 \%$

$60.9 \%$ 6

$31.0 \%$

$1.1 \%$

Table 2: If downloadable audio files (MP3 files and podcasts) were available to support your studies, what kind of material would you find useful?

Total

Respondents

Audio only - a full recording of each lecture provided on the course

48

Audio only - a short collection of the key learning points related

to a specific topic

Audio only - a short journalistic style interview with an expert

42

on a specific topic

Audio-visual material - audio material and powerpoint slides

Audio-visual material - audio material and video footage

Other

62

44

6

dropped. When it came to the kind of material students would prefer to see, there was no clear preference. As Table 2 demonstrates there was support for the idea of a full recording of a lecture, as well as the planned use of podules and audiovisual material to enhance powerpoint slides. Articulated Powerpoint slides that incorporate audio were ruled out due to technology and time constraints.

Following on from the online survey, we also gathered material from focus-groups made up of final year students. Two focus groups were convened at the start of the semester-two trials and two at the end. The main points from these groups were that having podcasts of the lecture, or the podules, was useful. One student stated that 'listening to the Podcasts was useful as a kind of consolidation of some of the more complex issues which arose in the module' (to listen to the podcasts, view the podlibrary and read the blog, see Lightfoot et al, 2009).

Of particular interest is the studentproduced podcasts, as they provided an innovative and interesting way for students to demonstrate achievement of the module aims, especially the ability to develop a reasoned argument, synthesise relevant information, exercise critical judgement and communicate effectively and fluently. According to one student these podcasts 'made learning the subject more of a proactive and engaging process, rather than simply absorbing designated information for analysis, by forcing us to discuss and decide what was worth focusing on, what wasn't and what else we could find that had been overlooked etc'.

In relation to attendance, we found some interesting comments. Students like going to lectures and therefore do not want them to be replaced by 
podcasts. 'Leeds is not a virtual university' as one said. Another said, 'I quite like going to lectures. I like listening to people. I like going to seminars as well. I like talking to people and interacting with people. Actually, I like getting a broad range of resources. It makes it more interesting if you've got a range of stuff to go to'. One anecdote at a conference was that it was like going to the cinema versus watching a dvd at home. You see the same film but sometime the collective cinema experience adds a new dimension (Kiernan, 2008).

Groups of students would decide how they wished their podcasts to be constructed (some chose interviews or three-way discussions) to best present the material. The session was then recorded by $\mathrm{Dr}$ Head and the podcast placed upon a module blog only accessible to students registered upon the module. These student-produced podcasts demonstrated excellent groupworking skills, initiative, self-organisation and time-management. Those students involved in creating these podcasts are very clear in statements attached that they have learnt new skills: 'You've got to be able to speak quite slowly and be coherent. ... Presentations where people actually see you is very different because it's kind of more personal'. Another argued, 'I think it may be even better than a seminar presentation because there you are maybe reading for ten minutes. Whereas this [ie a report on the seminar discussion] you are taking notes, you are contributing and then afterwards you are making a presentation that everyone is going to hear. ... It's much more demanding, it's a good idea. It's exercising skills that you don't really use that much'.

As stated above, one of the perceived advantages of podcasts is that they appeal to students with different learning styles and they also overcome the issue, associated with traditional lectures, that you only get one chance to hear them. One student said, 'I think it [a podcast] would be good because sometimes if the lecture goes too fast you can't actually take down the main point. So if you can pause it and play it whenever you want to then you can kind of note down the points at your own pace'. Another said, 'I found (the) week 8 (podcast) so helpful for recapping and filling in which bits I missed in the lecture'.

Podcasting lectures or seminars gives these students a choice about where and when to access digital material and how many times they wish to repeat it. Our findings support this literature. Student opinion was summarised by these statements: 'I think I would listen to it for example on the way into uni or into town ... so I can kill two birds with one stone'; or 'there is plenty of time to kill on the bus ... time's not an excuse not to listen particularly to a 5-min summary'. One interesting comment was that producing podcasts helped one student consider how the spoken word can differ from written text in putting across meaning appropriately for academia.

The module has traditionally stimulated independent learning and critical thinking. Seminars encourage students to examine the issues surrounding US foreign policy. However, students only get to hear the views of students in their own seminar group. Indeed the literature suggests that the true potential of podcasting technology lies in its knowledgecreation value, and its use as a vehicle for disseminating learner-generated content. As one student noted, podcasts allowed for 'a deepening and widening of debate and discussion beyond confines of seminar'. Another noted that the student podcast would be 'something different, to see what other opinions are in other seminar groups'.

Linked to this, the students expressed a preference for a podcast using an RSS

jason ralph et al european political science: 92010 
feed and thought this would make it easier and therefore more likely that they would use the additional material. 'It would be easier if it came to you on iTunes rather than having to seek it out every week' or 'it's nice to have it delivered to you, to use when you want'. It was interesting that most students listened to podcasts on computers. One said, 'I set up an RSS feed, and then listened on my laptop. I don't own an MP3 player, and I think its important to remember that not all students do, though I appreciate the majority probably do'. However, another interesting issue arose with some students stating that they did not want their private and university lives to mix. Their MP3 players were therefore for fun and entertainment, not for PIR podcasts!

Students thought podcasts could be made part of a structured learning process. Some asked for podules to be available prior to the lecture '. ... it's the habit you could get into, just listening to the summary before you walk into the seminar or walking on your way to the lecture. If you listen to the summary first you know what he is going to talk about and then you could maybe take it in a bit better'.

\section{SUMMARY AND CONCLUSIONS}

The above are the findings concerning the use of podcasts in one module at one university. However, they appear to replicate findings from other studies in the UK, USA and Australia (see Taylor, 2009). Our podcasting experience has met with a variety of reactions among students and staff. We have identified genuine benefits and concerns as voiced by students relating to the addition of podcasting to the range of methods currently used in academic teaching. These need to be taken seriously, but they do not rule out its further use as a learning and teaching tool.

\section{'There is, it seems, no obstacle either to replacing or to supplementing the traditional presentation with a student podcast'.}

Student opinion identified the lecturerproduced 'podules' as the most useful extra resource available to them (see also Roberts, 2008). The opportunity to 'listen again' even to just a short revision podcast was seen to be of benefit, although we were unable to establish any correlation between engagement with podcasts and improvements in marks. There was some anecdotal evidence that different learning styles were catered for but without a more formal analysis of the student learning styles before and after, this again is hard to corroborate.

We are conscious of the fact, however, that the present project has not integrated the podcasts into the module in a formal mark-bearing way. This has tended to put some students off fully engaging with the project, particularly those final year students who tend to look at this part of their degree rather instrumentally. A small core of students did engage enthusiastically with the project. They produced weekly podcasts of varying quality, but all of which engaged in an interesting way with the topic. The majority of students, however, appeared rather apathetic and did not really engage with the project despite being reminded. This suggests that unless the module is totally restructured around the use of podcasting there will be little uptake of the additional material provided. This tends to confirm the student comments as made in the initial focus groups. However, the technology has clearly worked and it has revealed the potential 
for, in particular, directly integrating student podcasts into the structure of the module. There is, it seems, no obstacle either to replacing or to supplementing the traditional presentation with a student podcast. Making this compulsory and assessing it would obviously increase student engagement with this practice. From our perspective and based on our initial impressions, these trials have clearly demonstrated that the technology can be used to assess presentation skills. Furthermore, the technology provides a record of presentations that can be consulted by external examiners in ways traditional classroom presentations cannot.
What we have discovered, however, is that it is both possible and desirable to take the next step and think of ways of integrating the practice of producing podcasts into the learning methods and objectives of PIR modules. Lee et al argue that podcasting allows 'students to articulate their understanding of ideas and concepts, and to share the outcomes with an audience they value, such as their peers' (Lee et al, 2008: 518). We concur with this argument, believing that the student act of producing podcasts can concentrate student minds on refining presentation and broader academic skills as well as enhancing their general learning experience.

\section{Notes}

1 Earlier versions of this article were presented to the E-learning Innovations within Politics panel at the 58th PSA Annual Conference 2008, Swansea, and at the 2nd Annual Interactive Poster ALIAS Session for ISA 2008 in San Francisco. This project was funded by the Subject Centre for Politics, C-SAP Tranche 7 Funding. Their support is acknowledged with thanks. Some of the findings have previously been explored in Lightfoot et al (2009). Thanks also go to Dr Esther Jubb and Simon Davis for their much appreciated assistance with the project.

2 The Informal Mobile Podcasting And Learning Adaptation (IMPALA) project investigates the impact of Podcasting on student learning and how the beneficial effects can positively be enhanced. See http:// www.impala.ac.uk/.

\section{References}

Beldarrain, Y. (2006) 'Distance education trends: integrating new technologies to foster student interaction and collaboration', Distance Education 27(2): 139-153.

Campbell, G. (2005) 'There is something in the air: podcasting in Education', EDUCAUSE Review 40(6): 32-47.

Chinnery, G. (2006) 'Emerging technologies: going to the MALL: mobile assisted language learning', Language Learning and Technology 10(1): 9-16.

Clark, S., Westcott, M. and Taylor, L. (2007) 'Using short podcasts to reinforce lectures', Paper presented at the 2007 National UniServe Conference, The University of Sydney.

Dolowitz, D. (2007) 'The big E: how electronic information can be fitted into the academic process', Journal of Political Science Education 3(2): 177-190.

Draper, S.W. and Maguire, J. (2007) 'Exploring podcasting as part of campus-based teaching', Practice and Evidence of the Scholarship of Teaching and Learning in Higher Education 12(1): 43-65.

Duke. (2005) Duke digital initiative, Duke University, Office of Information Technology. Available from: http://www.duke.edu/ddi/.

Edirisingha, P. and Salmon, G. (2007) 'Pedagogical model for podcasts in higher education', $L R A / B D R A$, May 2007.

Fox, R. and Ronkowski, S.A. (1997) 'Learning styles of political students', PS: Political Science and Politics 30(4): 732-737.

Gribbins, M. (2007) 'The perceived usefulness of podcasting in higher education: a survey of students' attitudes and intention to use', Paper presented at the Second Midwest United States Association for Information Systems, Springfield, IL, 18-19 May. 
Huann, T and Thong, M (2006) 'Audioblogging and podcasting in education', Education Ministry, Government of Singapore, http://www.moe.gov.sg/edumall/rd/litreview/audioblogg_podcast.pdf.

Kiernan, A. (2008) 'Can e-tools and the virtual learning environment successfully deliver active learning for active citizenship?', Paper presented at the 4th Annual Higher Education Academy Conference, Harrogate, 1-3 July.

Knight, R. (2006) 'Podcasting pedagogy divides opinion at US universities', Financial Times, 9 February.

Kumar, S. (2003) 'An innovative method to enhance interaction during lecture sessions', Advanced. Physiological Education 27: 20-25.

Lane, C. (2006) 'UW podcasting: Evaluation of year one', University of Washington. Available from: http://catalyst.washington.edu/research_development/papers/2006/podcasting_year1.pdf.

Lee, M., McLoughlin, C. and Chan, A. (2008) 'Talk the talk: learner-generated podcasts as catalysts for knowledge creation', British Journal of Educational Technology 39(3): 501-521.

Lightfoot, S.J., Ralph, J. and Head, N. (2009) 'Engaging students beyond the classroom: the experience of a podcasting project', Enhancing Learning in the Social Sciences 1(3): 169-180.

Lim, K.Y.T. (2006) 'Now hear this - exploring podcasting as a tool in geography education', in K. Purnell, J. Lidstone and S. Hodgson (eds.) Changes in Geographic Education: Past, Present and Future, Proceedings of the International Geographical Union Commission on Geographical Education Symposium, Brisbane, http://homepage.mac.com/voyager/brisbaneKenlim.pdf.

Meng, P. (2005) 'Podcasting and vodcasting', University of Missouri IAT Services White Paper.

Powner, L. and Allendoerfer, M. (2008) 'Evaluating hypotheses about active learning', International Studies Perspectives 9(1): 75-89.

Prensky, M. (2001) 'Digital natives, digital immigrants', On the Horizon 9(5): 1-6.

Read, B. (2005) 'Lectures on the go', Chronicles of Higher Education 52(10): 39-42.

Roberts, M. (2008) 'Adventures in podcasting', PS: Political Science and Politics 41: 585-593.

Sandars, J. and Schroter, S. (2007) 'Web 2.0 technologies for undergraduate and postgraduate medical education: an online survey', Postgraduate Medical Journal 83: 759-762.

SDDU. (2007) 'Podcasting', http://www.sddu.leeds.ac.uk/online_resources/podcasting/index.html.

Sims, R. and Sims, S. (1995) Importance of Learning Styles, Westport: Greenwood.

Singh, R. (2001) 'Teaching American Politics', Politics 21(2): 130-136.

Swain, H. (2006) 'Let them tune in', The Times Higher, 3 February. Summarised on http:// www.lums.lancs.ac.uk/news/7196/.

Taylor, M.Z. (2009) 'Podcast lectures as a primary teaching technology: results of a one-year trial', Journal of Political Science Education 5(2): 119-137.

Windham, C. (2007) 'Confessions of a podcast junkie', EDUCAUSE Review 42(3): 50-65.

\section{About the Authors}

Dr Jason Ralph is Senior Lecturer in International Relations and Director of Research in the School of Politics and International Studies, University of Leeds. His most recent publication is Defending the Society of States. Why America Opposes the International Criminal Court and its Vision of World Society (OUP, 2007).

Dr Naomi Head is Lecturer in International Studies in the School of Politics and International Studies at the University of Leeds. Her main research interests are critical international theory, conflict resolution and dialogue.

Dr Simon Lightfoot is Senior Lecturer in European Politics and Chair of the E-Learning Working Group in the School of Politics and International Studies at the University of Leeds. He is the author of Europeanising Social Democracy: The Rise of the Party of European Socialists? (Routledge, 2005). 